\title{
OXIDATIVE DNA DAMAGE AND MODULATION OF P53 TUMOR SUPPRESSOR GENE AS POSSIBLE MECHANISMS OF CHROMIUM CARCINOGENICITY( PART I)
}

\author{
By \\ ${ }^{1}$ Abd-El Maksoud NA, ${ }^{1}$ Zawilla NH, ${ }^{2}$ Taha FM and ${ }^{1}$ Seif Eldin AS \\ ${ }^{I}$ Occupational and Environmental Medicine Department Faculty of Medicine, Cairo University, \\ ${ }^{2}$ Medical Biochemistry Department Faculty of Medicine, Cairo University
}

\begin{abstract}
:
Introduction: Chromium, like many transition metal elements, is essential to life at low concentrations yet toxic to many systems at higher concentrations. Toxic effects of chromium can be classified into sensitizing, caustic and carcinogenic effects. Chromium is one of the best known sensitizing agents; it causes allergic dermatitis, allergic rhinitis and occupational asthma. There is sufficient evidence of the carcinogenicity of various chromium compounds in humans encountered via inhalation in industrial applications. Aim of work: to assess the carcinogenic potential of chromium exposure in tannery workers and study the possible mechanisms using 8-hydroxydeoxyguanosine (8-OHdG) which is one of the major oxidative adducts formed by radical induced damage to DNA, TAC (total anti-oxidant capacity) as a biomarker of cellular oxidative stress and p53 as apoptotic regulatory protein. Materials and methods: This work was carried out in twelve small-to medium-sized tanneries, in Misr Al Kadema district in Cairo. The study comprised of two groups, an exposed group (45 male workers) and a matched control group (30 male workers). All workers were subjected to a detailed history including present, past, family and occupational history. Clinical examination was performed with special emphasis on chest and skin examination. Laboratory investigations were performed in the form of kidney function test (blood urea and serum creatinine), blood level of TAC, P53 and chromium. Also, urinary 8-OHdG was done. Results: we found a significant increase in chromium, TAC, p53 and urinary 8-OHG in the exposed group compared to their referent control. Significant positive correlation was detected between P53 with blood level of TAC. Conclusion: Our results revealed that tannery workers have increased level of blood chromium, and this increase is associated with oxidative damage especially oxidative DNA damage reflected by elevated TAC serum level and
\end{abstract}


urinary 8-OHG. Also, up-regulation or activation of serum p53 in tannery workers which was positively correlated with chromium (non-significant) and significantly positively correlated with TAC reinforce the possible relation between oxidative stress induced by chromium exposure and carcinogenesis

Key words: Chromium, TAC (total anti-oxidant capacity), 8-OHG (8-hydroxydeoxyguanosine), DNA and p53.

\section{Introduction}

Chromium is a naturally occurring element in rocks, animals, plants, soil, and volcanic gases. It is one of the most abundant compounds in the earth's crust. It has the symbol $\mathrm{Cr}$ and atomic number 24. It is a steelygray, lustrous, hard metal that takes a high polish and has a high melting point (Kotaś and Stasicka, 2000).

Chromium is mined as chromite (FeCr2O4) ore. Chromium ores are mined today in South Africa,Zimbabwe, Finland, India, Kazakihstan and the Philippines. A total of 14 million tonnes of chromite ore is extracted. Reserves are estimated to be of the order of 1 billion tonnes with unexploited deposits in Greenland, Canada e USA (Mandina and Tawanda, 2013).

Chromium main uses are in alloys such as stainless steel, in chrome plating and in metal ceramics. Chromium is used in metallurgy to impart corrosion resistance and a shiny finish; as dyes and paints, its salts colour glass an emerald green and it is used to produce synthetic rubies; as a catalyst in dyeing and in the tanning of leather; to make molds for the firing of bricks. Chromium (IV) oxide $(\mathrm{CrO} 2)$ is used to manufacture magnetic tape (Zhang, et al., 2011).

Chromium occurs mainly in three forms. Metallic chromium $\mathrm{Cr}[0]$ is a steel-gray solid with a high melting point that's used to make steel and other alloys, chromium metal does not occur naturally it is produced from chrome ore. Trivalent chromium $\mathrm{Cr}$ (III) occurs naturally in rocks, soil, plants, animals, and volcanic emissions (Mandina and Tawanda, 2013). This form is believed by many to play a nutritional or pharmaceutical role in the body, Cr (III) is used industrially as a brick lining for high-temperature industrial furnaces and to make metals, metal alloys, and chemical compounds. Hexavalent chromium $\mathrm{Cr}$ (VI) is produced industrially when $\mathrm{Cr}$ (III) is heated in the presence of mineral bases and atmospheric oxygen. It is this third form of chromium that has proven 
to be of the greatest occupational and environmental health concern (Zhang, et al., 2011).

Exposure to chromium occurs through breathing, eating or drinking and through skin contact with chromium or chromium compounds. The level of chromium in air and water is generally low. In drinking water the level of chromium is usually low as well, but contaminated well water may contain the dangerous chromium (IV) (Guertin et al., 2004).

Effects of chromium on the skin include ulcerations, dermatitis, and allergic skin reactions. Inhalation of hexavalent chromium compounds can result in ulceration and perforation of the mucous membranes of the nasal septum, irritation of the pharynx and larynx, asthmatic bronchitis, bronchospasms and edema (Antonini et al., 2004).

It is widely recognized that hexavalent chromium is a carcinogen and that exposure significantly increases the risk of respiratory tract cancer. Moreover, Cr (VI) causes chromosome aberrations, sister chromatid exchanges, gene mutation and cell death (Kuo et al., 2003). This process generates a cascade of events due to chromium (VI)-induced oxidative stress with enhanced production of superoxide anion and hydroxyl radicals, increased lipid peroxidation and genomic DNA fragmentation, modulation of intracellular oxidized states, activation of protein kinase $\mathrm{C}$, apoptotic cell death and altered gene expression (Bagchi et al., 2001).

Analysis of a form of oxidative DNA damage by assessing concentrations of 8-hydroxydeoxyguanosine OHdG) may be a biomarker of cellular oxidative stress during carcinogenesis of chromium (Kuo et al., 2003).

Other studies highlighted that apoptotic regulatory protein p53 may play a major role in chromium (VI)induced oxidative stress and toxicity. So taken together, oxidative stress and oxidative tissue damage, and a cascade of cellular events including modulation of apoptotic regulatory gene p53 are involved in chromium (VI)-induced toxicity and carcinogenesis (Bagchi et al., 2001).

\section{Aim of Work}

To assess the carcinogenic potential of chromium and study 
the possible mechanisms using 8-hydroxydeoxyguanosine (8-OHdG) which is one of the major oxidative adducts formed by radical induced damage to DNA, TAC (total antioxidant capacity) as a biomarker of cellular oxidative stress and p53 as apoptotic regulatory protein.

\section{Materials and Methods}

Study design: Case-control study.

Study place and duration of the study: This work had been conducted at five small-to medium-sized Egyptian tanneries, in Misr Al kadema area in Cairo, an area which contains most of the private sector for leather tanning plants in Egypt. From June 2012 to June 2014.

Study sample: The exposed group comprised of forty five workers that fulfilled eligibility for inclusion. The control group comprised thirty male workers randomly selected from administration and security personnel from an insurance company and never occupationally exposed to tanning and fulfilled eligibility for inclusion. The control group was matched to the exposed group as regards age, sex, socioeconomic status and smoking habits.
Inclusion criteria for exposed group were working in tanneries for at least the proceeding five years. While exclusion criteria for both exposed and control subjects were occupational exposure to oxidants or genotoxins, smoking, chronic liver or kidney diseases, diabetes or immunological disorders or regular intake of antioxidants or immunosuppressive drugs.

The studied groups were subjected to the following:

\section{1-A self designed questionnaire} including inquiries about age, sex, occupational history and special habits. Also, present, past and family history was taken.

\section{2-Clinical examination for:}

Vital signs: pulse, blood pressure, respiratory rate and temperature.

Eye: redness and tearing

Skin: redness, dryness, cracks and scaring.

Neurological: Mood, intelligence, cooperation, attention, orientation of time, place \& persons, equilibrium and sensory affection.

Chest: cough and wheezes. 


\section{3-Laboratory investigations:}

\section{A- Blood sample collection:}

From each subject $10 \mathrm{cc}$ of venous blood were taken through a vein puncture using a dry plastic disposable syringe under complete aseptic conditions. The blood was kept in a tube and allowed to clot then centrifuged for separation of the serum for determination of the following biochemical parameters serum chromium level, serum p53 and TAC (total antioxidant capacity).

\section{B- Urine sample collection:}

A urine sample was collected from each subject, in a sterile container for measuring of 8-hydroxydeoxyguanosine (8-OHdG).All subjects washed their hands with soap and water prior to sample collection to avoid contamination.

The samples for blood chromium level were prepared by dilution of 0.5 $\mathrm{ml}$ of blood with $2 \mathrm{ml}$ deionized water. The chromium in blood was measured by graphite furnace atomic absorption spectrophotometer

(Perkin-Elmer model 5100PC, Norwalk, CT).

Assement of human P53 protein in serum using ELISA principle: An anti-human p53 coating antibody is adsorbed onto Human p53 present in the sample or standard binds to antibodies adsorbed to the microwells. A biotin-conjugated anti-human p53 antibody is added and binds to human p53 captured by the first antibody. A spectrophotometer using $450 \mathrm{~nm}$ as the primary wave length (optionally $620 \mathrm{~nm}$ as the reference wave length; $610 \mathrm{~nm}$ to $650 \mathrm{~nm}$ is acceptable). Blank the plate reader according to the manufacturer's instructions by using the blank wells. Determine the absorbance of both the samples and the standards (eBioscience company).

8 - hydroxydeoxyguanosine principle: $8-\mathrm{OHdG}$ ELISA kit applies the quantitative sandwich enzyme immunoassay technique. The microtiter plate has been pre-coated with a monoclonal antibody specific for $8-\mathrm{OHdG}$. Standards or samples are then added to the microtiter plate wells and $8-\mathrm{OHdG}$ if present, will bind to the antibody pre-coated wells. In order to quantitatively determine the amount of $8-\mathrm{OHdG}$ present in the sample, a standardized preparation of horseradish peroxidase (HRP)conjugated polyclonal antibody, specific for $8-\mathrm{OHdG}$ are added to each well to "sandwich" the 8-OHdG immobilized 
on the plate. The microtiter plate undergoes incubation, and then the wells are thoroughly washed to remove all unbound components. Next, substrate solutions are added to each well. The enzyme (HRP) and substrate are allowed to react over a short incubation period. Only those wells that contain 8-OHdG and enzyme-conjugated antibody will exhibit a change in color. The enzyme-substrate reaction is terminated by addition of a sulphuric acid solution and the color change is measured spectrophotometrically at a wavelength of $450 \mathrm{~nm}$ (BlueGene Biotech.company).

Total Antioxidant Capacity (TAC) principle: Fast colorimetric/ photometric test: The determination of the total antioxidative capacity is based on the reaction of peroxides with peroxidase followed by a color reaction of the chromogenic substrate tetramethylbenzidine. Its blue color turns to yellow after addition of the stop solution and can be measured photometrical at $450 \mathrm{~nm}$ (Alternatively kinetic measurements at $600 \mathrm{~nm}$ are possible, if end point measurement is not wanted. In case of end point measurement (use of stop solution) samples with absorptions at $450 \mathrm{~nm}$ like sera have to be assayed by subtraction of initial absorption. Quantification is achieved by serial dilutions of a standard Antioxidant-solution (LDN: Labour Diagnostika Nord company).

\section{Statistical analysis}

Data obtained from the study was coded and entered using the statistical package SPSS version 15. The mean values, standard deviation (SD) and ranges were then estimated for quantitative variables. Qualitative data was expressed as frequency distribution. Comparisons between exposed and control groups were done using Chi Square $(\chi 2)$ test for qualitative variables and using the independent simple t-test as well as the analysis of variance (ANOVA test) followed by Post Hoc test for normally distributed quantitative variable. The non-parametrical MannWhitney test was used for quantitative variables not normally distributed. Correlations were done to test for the presence of linear relations between quantitative variables. P-values less than 0.05 and less than 0.005 were considered statistically significant and highly significant, respectively. 


\section{Consent}

Authors declare that a verbal consent was taken from the studied group, confidentiality was maintained.

\section{Ethical approval}

The study protocol was approved by Occupational and Environmental Department Ethical Committee, Faculty of Medicine, Cairo University.

\section{Results}

All the studied group were males, mean age of exposed workers was $33.07 \pm 11.05$ years ranging from (1749) years. Mean duration of exposure was $15.64 \pm 7.63$ years ranging from (530) years. The mean age of the control group was $31.90 \pm 10.81$ years, ranging from (20-55) years.

Table (1): prevalence of respiratory manifestations among studied groups:

\begin{tabular}{|l|c|c|c|c|}
\hline $\begin{array}{l}\text { Clinical } \\
\text { Manifestations }\end{array}$ & $\begin{array}{c}\text { Exposed(n=45) } \\
\mathbf{N}(\%)\end{array}$ & $\begin{array}{c}\text { Control(n=30) } \\
\mathbf{N}(\%)\end{array}$ & $\mathbf{X}^{2}$ & $\mathbf{P}$ \\
\hline Allergic rhinitis & $16(35.6)$ & $2(6.6)$ & 0.032 & $*<\mathbf{0 . 0 5}$ \\
\hline Dry cough & $20(44.4)$ & $6(20)$ & 0.047 & $*<\mathbf{0 . 0 5}$ \\
\hline Expectoration & $18(40)$ & $2(6.6)$ & 0.035 & $*<\mathbf{0 . 0 5}$ \\
\hline Asthmatic attacks & $20(44.4)$ & $6(20)$ & 0.047 & $* *<\mathbf{0 . 0 1}$ \\
\hline Chronic bronchitis & $30(66.7)$ & $8(26.7)$ & 0.001 & $* * \leq \mathbf{0 . 0 1}$ \\
\hline
\end{tabular}

$*$ Significant $\leq 0.05$.

** High significant $\leq 0.01$.

Table (1) showed that all respiratory manifestations were significantly higher among the exposed group. 
Table (2): Non-respiratory manifestations among studied groups:

\begin{tabular}{|l|c|c|c|c|}
\hline & $\begin{array}{c}\text { Exposed } \\
\mathbf{N}(\boldsymbol{\%})\end{array}$ & $\begin{array}{c}\text { Control } \\
\mathbf{N}(\boldsymbol{\%})\end{array}$ & $\mathbf{X}^{\mathbf{2}}$ & $\mathbf{P}$ \\
\hline High blood pressure( $\geq \mathbf{1 4 0 / 9 0 )}$ & $16(35.6)$ & $5(16.7)$ & 0.074 & $>0.05$ \\
\hline Eye manifestation & $17(37.8)$ & $6(20)$ & 0.102 & $>0.05$ \\
\hline $\begin{array}{l}\text { Skin manifestation (Contact } \\
\text { dermatitis) }\end{array}$ & $20(44.4)$ & $6(20)$ & 0.047 & $*<\mathbf{0 . 0 5}$ \\
\hline
\end{tabular}

*Significant $\leq 0.05$.

Table (2) showed almost half of the exposed workers (44.4\%) showed manifestation of allergic contact dermatitis which was significantly higher than control group $(\mathrm{p}<0.05)$. However, there was no significant difference between both groups as regards prevalence of hypertension or eye manifestations.

Table (3): Mean (SD) of serum chromium, 8-OHG, TAC and p53 in the exposed and control groups:

\begin{tabular}{|l|c|c|c|c|}
\hline & $\begin{array}{c}\text { Exposed } \\
(\mathbf{n = 4 5}) \\
\text { Mean } \pm \text { SD }\end{array}$ & $\begin{array}{c}\text { Control } \\
(\mathbf{n}=\mathbf{3 0}) \\
\text { Mean } \pm \text { SD }\end{array}$ & t-test & $\mathbf{P}$ \\
\hline Chromium( $\mathbf{\mu g} / \mathbf{L})$ & $0.75 \pm 0.37$ & $0.27 \pm 0.07$ & -5.74 & $* *<\mathbf{0 . 0 1}$ \\
\hline $\mathbf{8 - O H G ( n g / m L )}$ & $1.73 \pm 0.42$ & $0.78 \pm 0.35$ & -6.81 & $* *<\mathbf{0 . 0 1}$ \\
\hline TAC(mmol/L) & $1.26 \pm 0.59$ & $2.12 \pm 0.651$ & -4.48 & $* *<\mathbf{0 . 0 1}$ \\
\hline P53(U/mL) & $4.55 \pm 3.27$ & $0.78 \pm 0.35$ & -5.12 & $* *<\mathbf{0 . 0 1}$ \\
\hline
\end{tabular}

** High significant $\leq 0.01$.

N.B:8-OHG=8-oxyhydroxyguanisine

TAC $=$ Total antioxidant capacity .

Table 3 shows that serum chromium, 8-OHG and P53 levels were significantly higher among the exposed group, while TAC was significantly lower $(\mathrm{p}<0.01)$. 
Table (4): Pearson correlation between age, duration of work and laboratory parameters in exposed workers:

\begin{tabular}{|l|c|c|c|c|c|c|c|c|}
\hline \multirow{2}{*}{} & \multicolumn{2}{|c|}{ Chromium } & \multicolumn{2}{c|}{ TAC } & \multicolumn{2}{c|}{ P53 } & \multicolumn{2}{c|}{ 8-OHG } \\
\cline { 2 - 8 } & $\mathbf{R}$ & $\mathbf{P}$ & $\mathbf{R}$ & $\mathbf{P}$ & $\mathbf{R}$ & $\mathbf{P}$ & $\mathbf{R}$ & $\mathbf{P}$ \\
\hline \multirow{2}{*}{ Age } & 0.27 & $>0.05$ & -.025 & $>0.05$ & 0.145 & $\begin{array}{c}>0.05- \\
\text { sign. }\end{array}$ & -.007 & $>0.05$ \\
\hline $\begin{array}{l}\text { Duration } \\
\text { of work }\end{array}$ & 0.29 & $>0.05$ & 0.061 & $>0.05$ & 0.29 & $*<\mathbf{0 . 0 5}$ & 0.019 & $>0.05$ \\
\hline Chromium & & & 0.33 & $*<\mathbf{0 . 0 5}$ & 0.25 & $>0.05$ & 0.24 & $>0.05$ \\
\hline TAC & 0.33 & $*<\mathbf{0 . 0 5}$ & & & 0.36 & $*<\mathbf{0 . 0 5}$ & -.043 & $>0.05$ \\
\hline P53 & 0.25 & $>0.05$ & 0.36 & $*<\mathbf{0 . 0 5}$ & & & 0.12 & $>0.05$ \\
\hline 8-OHG & 0.24 & $>0.05$ & -0.43 & $>0.05$ & 0.127 & $>0.05$ & & \\
\hline Urea & 0.01 & $>0.05$ & 0.017 & $>0.05$ & 0.25 & $>0.05$ & -0.056 & $>0.05$ \\
\hline Creatinine & -0.05 & $>0.05$ & -0.29 & $*<\mathbf{0 . 0 5}$ & -.026 & $>0.05$ & .169 & $>0.05$ \\
\hline
\end{tabular}

* Significant $\leq 0.05$.

Table 4 shows significant positive correlations was found between serum chromium level and TAC and between p53 and both duration of work and TAC. A significant negative correlation was found between TAC and serum creatinine. 
Table (5): Linear regression analysis to test predictor for serum levels of serum P53, 8-OHG and TAC in exposed workers:

\begin{tabular}{|l|c|c|c|}
\hline & B & t-test & P \\
\hline TAC & & & \\
Age & & -0.760 & $>0.05$ \\
Exposure & -0.005 & -5.837 & $*<\mathbf{0 5}$ \\
Duration of work & -0.849 & -0.128 & $>0.05$ \\
\hline 8-OHG & -0.002 & & \\
Age & & -0.728 & $>0.05$ \\
Exposure & -0.003 & 10.255 & $>0.05$ \\
Duration of work & 0.954 & -0.328 & \\
\hline & -0.003 & & $>0.05$ \\
P53 & & & $* 0.05$ \\
Age & & 471 & $>0.05$ \\
Exposure & 0.013 & 4.779 & \\
Duration of work & 2.897 & 1.594 & \\
& 0.107 & & \\
\hline
\end{tabular}

* Significant $\leq 0.05$.

In this table linear regression analysis was done to test significant predictor for serum levels of TAC, 8-OHG and p53. It was found that occupational exposure to chromium was the only predictor (rather than age and duration of work) to the high level of TAC, 8-OHG and p53.

\section{Discussion}

In our study, chromium level was statistically significantly higher among exposed workers compared to the control $[0.75 \pm 0.37$ compared to $0.27 \pm 0.07(\mathrm{P}<0.001)]$. Our results are in agreement with Shouman and coworkers, 1999 who found higher mean levels of blood and urine chromium in the tannery workers than controls (Shouman et al., 1999).
Also, Simpson and Gibson in 1992 measured concentrations of chromium in hair, serum, and urine of men who were previously employed in the leather tanning industry. Concentrations of chromium in hair and serum were significantly lower than corresponding values obtained during their employment and were comparable to levels obtained for controls in a previous study (the 
value of chromium in hair was $25 \pm 4.0$ $\mathrm{nmol} / \mathrm{g}$ compared to $26 \pm 3.0 \mathrm{nmol} / \mathrm{g}$ during employment, while serum level was $5.6 \pm 1.0 \mathrm{nmol} / \mathrm{L}$ compared to $5.8 \pm 1.0$ during employment and urine level was $3.8 \pm 1.0 \mathrm{nmol} / \mathrm{L}$ compared to $4.2 \pm 3.8 \mathrm{nmol} / \mathrm{L}$ during employment) (Simpson and Gibson, 1992).

Recently a study in North India investigated the genotoxicity and oxidative stress in chromium exposed tannery workers. The exposed group showed significantly higher level of chromium $(\mathrm{P}<0.001)$ compared to control (Ambreen et al., 2014).

The prevalence of respiratory tract disorders is significantly higher among tannery workers compared to the control group (table 1).This agrees with a study done by Khan et al., 2013, who found that about one third of cement and tannery workers had severe asthmatic chest manifestations and severe nasal allergic manifestations in $22.7 \%$ and $20 \%$ of cement and tannery workers, respectively. Similarly, results of another study on tannery workers in Pakistan revealed that $12 \%$ of exposed workers had chronic bronchitis and these results were associated with high blood and urinary chromium levels (Elhosary et al., 2014).
Additionally there was significant difference between both groups as regards presence of contact dermatitis. The results revealed that 20(44.4\%) of the exposed group were suffering from dermatitis, compared to $6(20 \%)$ of the control group.

Comparable to our results Khalil et al., 1999, studied two groups of workers, the first included chrome tanning workers and the second cementexposed workers in the construction process. The results of this study demonstrated that $24.1 \%$ of examined workers were clinically diagnosed as contact dermatitis, whereas, $31.33 \%$ of the exposed workers manifested positive patch test reaction (Khalil et al., 1999).

Also, a case-control study was performed in 2014 on 155 dermatitis patients with positive patch test reactions to potassium dichromate and a matched control group of 621 dermatitis patients. Their results were, $66 \%$ of chromium allergic patients had a positive history of contact dermatitis caused by leather exposure, with higher prevalence of dermatitis during the last year $(p=0.008)$ than patients in the control group. So they concluded 
that chromium-allergic patients have more severe and more chronic contact dermatitis due to their primary chromium exposure from leather articles (Bregnbak et al., 2014).

The role of p53 in ensuring longevity through prevention of cancer is well established. P53 activates a cellular response to DNA damage that leads to a halt in proliferation, via apoptosis or senescence, and is considered a powerful barrier to tumor development (Soussi et al., 2001).

In the present study, statistically significant increase in p53 was detected among exposed group compared to their control. This increase was positively correlated to level of chromium.

A number of studies have noted that chromium exposure resulted in the up regulation and/or activation of p53 (Bagchi et al., 1997, Carlisle and Pritchard, 2000 and Russo et al., 2005).The results were consistent with reactive chromium species as important drivers of that activation. About half of cement and one third of tannery groups expressed high grade of p53 expression in one study (Khan et al., 2013).
In this study, we observed that there was a significant increase in the level of 8-Hydroxydeoxyguanosine in urine and significant reduction in the serum TAC, which indicates a state of oxidative stress. ROS (Reactive Oxygen Species) have been implicated in the toxicity of chromium (VI) by several authors (Miesel et al., 1995 and O'Brien et al., 2003). Their formation with subsequent cellular damage is considered as the common molecular mechanism of $\mathrm{Cr}$ (VI)-induced toxicity and carcinogenicity. According to this hypothesis, chromium (VI) itself is not a cytotoxic agent but rather an oxygen free radical generator through cellular reduction to chromium (VI) (Kadiiska et al., 1994). Chromium reduction intermediates are believed to react with hydrogen peroxide to form the hydroxyl radical (HO) (Yao et al., 2008), which may finally attack proteins, DNA, and membranes lipids thereby disrupting cellular functions and integrity (O'Brien et al., 2003).

In our study there was a statistically significant decrease in TAC (one index of antioxidant activity) in exposed group compared to their control. Interestingly this decrease was 
associated with a significant positive correlation between TAC and serum level of chromium. As the TAC has a protective role against oxygen free radical-induced damage, its decrement can be understood as a response to overconsumption due to oxidative stress. However the significant positive correlation with chromium could be explained as an adaptive response with prolonged exposure to chromium and as a defense against chromiuminduced oxidative stress. This is in accordance with a study done by Simpson and Gibson, 1992, who found significant correlation between DNA damage and oxidative stress parameters malondialdehyde

(MDA), and antioxidants:

glutathione (GSH) and superoxide dismutase (SOD) in one hand and chromium level in blood and duration of exposure on the other hand among the exposed group.

Comparable to our results, blood chromium levels ranging from 4.42 to $10.6 \mu \mathrm{g} / \mathrm{L}$, induced oxidative stress with marked significantly increased lipid peroxidation, decreased plasma antioxidant capacity

(PAC) and plasma total thiol (SH groups) in exposed compared to controls (Patlolla et al., 2009).
In an experimental study, $\mathrm{Cr}$ (VI) could induce dose- and time-dependent effects on DNA damage, however contrary to our results both liver and kidney showed defense against chromium-induced oxidative stress by enhancing their antioxidant enzyme activity which was explained as an adaptive response to oxidative stress (Zendehdel et al., 2014)

Indeed, exposure to redox-active transition metals leads to increased production of reactive oxygen species, which in turn may cause oxidative DNA lesions that may contribute to the pathology of cancer (Marnett 2000). 8-Hydroxydeoxyguanosine (8-OHdG) is one of the base modifications resulting from oxidative DNA lesions and its abundance is therefore a reflection of oxidant-induced alterations in the genetic material (Chan-Young et al., 2012). Our results agree with another study done by Zhao et al., 2014, they studied the effect of repeated chromium inhalation in rats. The study deduced overproduction of cellular ROS due to chromium exposure resulting in genomic DNA oxidative damage appeared in form of increased urinary 8-OHdG level. 
Occupational and/or environmental exposures to chromium have been implicated in the development of numerous health outcomes, including various forms of cancer. However, even though hexavalent chromium is an established human carcinogen, the precise mechanism/s by which it exerts the carcinogenic effects are not fully understood. The results of the current study throw some light on the adverse health effects of chromium exposure in tannery workers with special emphasis on the carcinogenic potential and the possible role of oxidative stress and oxidative DNA damage in pathogenesis.

\section{Conclusion and Recommendations}

Tannery workers are exposed to markedly higher level of chromium which is associated with significantly higher prevalence of respiratory disorders such as rhinitis, asthma and chronic bronchitis than controls. Also, there was a higher prevalence of occupational dermatoses in the form of contact dermatitis. Moreover, both urinary level of 8-OHG an index of oxidative DNA damage, blood level of P53 (a tumor suppressor protein) were also markedly elevated among workers than controls, with marked decrease of serum TAC (index of antioxidant). So urinary 8-OHG or serum TAC can be used as indices of oxidative damage induced by occupational exposure to chromium in leather tanning industry. Regular health education and training for workers about health hazards of chromium and the benefit of safe work practices is mandatory. Encourage the use of personal protective equipments. Regular environmental monitoring which should not exceed the permissible exposure limits.

\section{References}

1. Ambreen $\mathrm{K}$, Khan F, Bhadauria $\mathrm{S}$ and Kumar S (2014): Genotoxicity and oxidative stress in chromium-exposed tannery workers in north India. Journal of Toxicology Indian Health; 30 (5): 405-414.

2. Antonini J, Taylor M, Zimmer A and Roberts J (2004): Pulmonary responses to welding fume: role of metal constituents. Journal of Toxicology and Environmental Health; 67: 233- 249.

3. Bagchi D, Bagchi M and Stohs SJ (2001): Chromium (VI)-induced oxidative stress, apoptotic cell death and modulation of p53 tumor suppressor gene. Journal of Molecular Cell Biochemistry; 222(1-2):149-58.

4. Bagchi D, Vuchetich PJ, Bagchi M, Hassoun EA, Tran MX, Tang L and Stohs SJ (1997): Induction of oxidative stress by chronic administration of sodium dichromate (chromium VI) and cadmium chloride (cadmium II) to rats. Journal of Free Radical Biology Medicine; 22:471-478.

5. BlueGene Biotech.company: http://www. elisakit.cc/products.asp?classid $=61$. 
6. Bregnbak D, Jacob T, Claus Z and Jeanne J (2014): Characteristics of chromiumallergic dermatitis patients prior to regulatory intervention for chromium in leather: a questionnaire study. Journal of Contact Dermatitis; 71 (5): 255-317.

7. Carlisle DL and Pritchard DE (2000): Chromium (VI) induces p53-dependent apoptosis in diploid human lung and mouse dermal fibroblasts. Journal of Molecular Carcinogenesis; 28:111-118.

8. Chan-Young O, Eun-Hee K, Duck JC, Ho JL, Ki-Baik H, and Myung HC (2012):8-Hydroxydeoxyguanosine: Not mere biomarker for oxidative stress, but remedy for oxidative stress-implicated gastrointestinal diseases. Journal of World Gastroenterology; 18(4): 302-308.

9. eBioscience company: http://www.affymetrix. com/estore/ebioscience/index.affx

10. Elhosary N , Maklad A, Soliman E, ElAshmawy N and Oreby M(2014): Evaluation of oxidative stress and DNA damage in cement and tannery workers in Egypt. Journal of Inhalation toxicology; 26 (5):289-298.

11. Guertin J, James A and Cynthia P (2004): Chromium (VI) Handbook Chapter; 1(2):33-45.

12. Kadiiska MB, Xiang QH and Mason RP (1994): In vivo free radical generation by chromium (VI): An electron spin resonance spin-trapping investigation. Journal of Chemistry Research Toxicology; 7:800-805.

13. Khalil SB, Shouman AE, El Sayed HM and Moussa EM (1999): Chromium-induced contact dermatitis and indices for diagnosis. Journal of Egyptian public health association; 5:485-501.

14. Khan DA , Shahida M, Farooq AK and Muhammad QA(2013):Toxic effects of chromium on tannery workers at Sialkot (Pakistan). Journal of Toxicology and Industrial Health; 29(2):209-215.
15. Kotaś J and Stasicka Z (2000): Chromium occurrence in the environment and methods of its speciation. Journal of Environmental Pollution; 107 (3): 263-283.

16. Kuo HW, Chang SF, Wu KY and Wu FY (2003): Chromium (VI) induced oxidative damage to DNA: increase of urinary 8-hydroxydeoxyguanosine concentrations (8OHdG) among electroplating workers. Journal of Occupational and Environmental; 60:590594.

17. LDN: Labour Diagnostika Nord company: http://www.medica-tradefair.com/cipp/ show,lang,2/oid,28563/xa_nr,2388352/ /WebExhDatasheet/exh_datasheet

18. Mandina S and Tawanda M (2013): Chromium, an essential nutrient and pollutant: A review. African Journal of Pure and Applied Chemistry; 7(9): 310-317.

19. Marnett LJ (2000): Lipid peroxidation-DNA damage by malondialdehyde. Journal of Mutation Research Journal; 424 (1-2):83-95

20. Miesel R, Kroger H, Kurpisz M and Wesser U (1995): Induction of arthritis in mice and rats by potassium peroxochromate and assessment of disease activity by whole blood chemiluminescence and 99mpertechnetateimaging. Journal of Free Radical Research; 23:213-227.

21. O'Brien TJ, Ceryak S and Patierno SR (2003): Complexities of chromium carcinogenesis: Role of cellular response, repair and recovery mechanisms. Journal of Mutation Research; 533:3-36.

22. Patlolla AK, Barnes C, Yedjou C, Velma VR and Tchounwou PB (2009): Oxidative stress, DNA damage, and antioxidant enzyme activity induced by hexavalent chromium in SpragueDawley rats. Journal of Environmental toxicology; 24(1), 66-73. 
23. Perkin-Elmer model 5100PC, Norwalk, CT: https://www.google.com.eg/ search?q=\%28Perkin-Elmer + model $+5100 \mathrm{PC}$ ,+Norwalk,+CT\&ie $=$ utf- $8 \&$ oe $=u t f-8 \& g_{\text {w }}$ $r d=c r \& e i=O L V 1 V K C W J Y n \cdot U u S V g \wedge A J$

24. Russo P, Catassi A, Cesario A, Imperatori A, Rotolo N, Fini $\mathrm{M}$ and Dominioni L (2005): Molecular mechanisms of hexavalent chromium- induced apoptosis in human broncho-alveolar cells. Journal of American Respiratory Cell Molecular Biology; 33:589_ 600 .

25. Shouman AE, Abdel Karim AH, Gadallah MA, Al- Ansary MS and Kalil SB (1999): Health hazards among workers of tanning. Journal of Egypt Community Medicine; 17 (1):17-23.

26. Simpson JR and Gibson RS (1992): Hair, serum, and urine chromium concentrations in former employees of the leather tanning industry. Journal of Biological trace elements research; 32:155-159.

27. Soussi T and Béroud C (2001): Assessing TP53 status in human tumors to evaluate clinical outcome. Journal of Nature Reviews Cancer J; 1: 233-239

28. Yao H, Guo L, Jiang BH, Luo J and Shi X (2008): Oxidative stress and chromium (VI) carcinogenesis. Journal of Environmental Pathology and Toxicology Oncology; 27:7788.

29. Zendehdel R, Seyed V, Mansoor R, Vajihe H, and Hamidreza M (2014): Chemometrics models for assessment of oxidative stress risk in chrome-electroplating workers. Journal of Drug and Chemical Toxicology; 1-6.

30. Zhang X, Xuan Z, Xu C, Li-Fen Z, Zhang-Ping Y, Cai-Xia J et al.,(2011): Chronic occupational exposure to hexavalent chromium causes DNA damage in electroplating workers. Journal of BMC Public Health; 11: 224.

31. Zhao L, Yanshuang S, Ji P, Jian G, Yun W, Zhangjian C et al., (2014): Effects of repeated $\mathrm{Cr}$ (VI) intratracheal instillation on club (Clara) cells and activation of nuclear factor-kappa B pathway via oxidative stress. Journal of Toxicology Letters; 231(1): 72-81 